\title{
Salvage chemotherapy for the treatment of Leukemia cutis in a patient with acute monocytic leukemia
}

\author{
Mehrdad Payandeh ${ }^{1}$, Afshin Karami ${ }^{2}$, Noorodin Karami ${ }^{3}, *$, Soode Enayati ${ }^{4}$, Mehrnoush Aeinfar $^{1}$
}

${ }^{1}$ Department of Hematology and Medical Oncology, Kermanshah University of Medical Sciences, Kermanshah, Iran

${ }^{2}$ Department of Hematology, Shahid Beheshti University of Medical Sciences, Tehran, Iran

${ }^{3}$ Department of Genetics, Shahid Sadoughi University of Medical Sciences, Yazd, Iran

${ }^{4}$ Department of Biotechnology, Science and Research Branch, Islamic Azad

University, Tehran, Iran

Correspondence

Noorodin Karami, Department of Genetics, Shahid Sadoughi University of Medical Sciences, Yazd, Iran

Email: noorodin.karami@yahoo.com

History

- Received: Dec 04, 2018

- Accepted: Jan 21, 2019

- Published: Jan 30, 2019

DOI :

https://doi.org/10.15419/bmrat.v6i1.517

\section{Check for updates}

Copyright

(c) Biomedpress. This is an openaccess article distributed under the terms of the Creative Commons Attribution 4.0 International license.

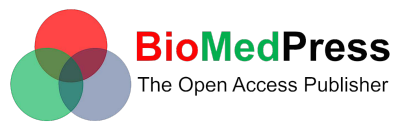

ABSTRACT

Leukemia cutis (LC) is a rare disorder that is distinguished by the infiltration of leukemic cells into the skin. This can be a manifestation of relapse of the previously treated leukemia. We report a case of a 70-year-old woman with acute monocytic leukemia (AMOL), whose disease relapsed and developed into LC after a successful induction therapy. Salvage chemotherapy has been applied successfully to prevent the development of LC in the patient's skin.

Key words: Cutis, Leukemia, Monocytic, Salvage chemotherapy

\section{INTRODUCTION}

Leukemia cutis (LC) is known as a general term for skin lesions caused by leukemia ${ }^{1}$. In general, this disorder has an incidence of $2.9 \%-3.7 \%$ in patients with acute myeloid leukemia (AML) ${ }^{2,3}$. Therefore, AML is the second most common leukemia associated with leukemia cutis ${ }^{4}$. Due to a wide range of skin lesions in leukemia cutis, its diagnosis is undistinguishable from other skin disorders. In these cases, immunohistochemistry (IHC) stains can be helpful in the diagnosis of this disease ${ }^{5}$. Since leukemia cutis may be a sign of a systemic disorder that occurs before, after, or concurrently with the beginning of AML, treatments should focus on the eradication of systemic leukemia ${ }^{6}$. This paper reports a case of leukemia cutis, which occurred after the diagnosis of AML.

\section{CASE PRESENTATION}

In February 2018, a 70-year-old woman was referred to the Clinic of Hematology and Oncology of Kermanshah with pain, fatigue, night sweats and loss of appetite. The laboratory tests showed a marked leukopenia $\left(1.8 \times 10^{9} / \mathrm{L}\right)$, anemia $(10.1 \mathrm{~g} / \mathrm{dL})$ and thrombocytopenia $\left(145 \times 10^{9} / \mathrm{L}\right)$, and a blood film showed $15 \%$ of circulating blast cells (Figure 1).

The examination of the bone marrow aspiration (BMA) and bone marrow biopsy (BMB) revealed a hypocellular bone marrow along with a high percentage of blast cells ( $>30 \%$ of monoblast cells). These cells were positive for CD33, CD45, CD68, and lysosomes. According to FAB (French-American-British) classifications, these results were compatible with AML-M5 and treatment was started immediately with azacytidine-based regimens such as CAG (cytarabine, aclarubicin, and G-CSF). After three cycles, the full blood count (FBC) was as follows:

WBC: $3 \times 10^{9} / \mathrm{L}, \mathrm{Hb}: 11 \mathrm{~g} / \mathrm{dL}$ and Plt: $275 \times 10^{9} / \mathrm{L}$.

The results demonstrated a relatively good response to treatment. Four months following the initiation of chemotherapy, the patient referred to the dermatologists with a 2-week history of multiple skin lesions such as erythematous and papulonodular rashes on face and neck (Figure 2).

Physical and laboratory examinations revealed gum hypertrophy along with severe leukopenia and raised lactate dehydrogenase levels. Hence, the skin biopsy was performed from suspicious skin lesions on the face, which showed an extensive leukemic cell infiltration into the dermis and the subcutaneous tissues. The results indicated the clear signs of relapsed acute monocytic leukemia LC. The patient was treated with a course of FLAG chemotherapy (fludarabine 30 $\mathrm{mg} / \mathrm{m}^{2}$, Ara-C $1 \mathrm{~g} / \mathrm{m}^{2}$ for five days, and granulocytecolony stimulating factors from day six until neutrophil recovery). The patient's leukemia cutis lesions were resolved within two weeks after the initiation of FLAG chemotherapy, and the patient is a now under follow-up (Figure 3).

\section{DISCUSSION}

One of the well-known manifestations of extramedullary AML is leukemia cutis that occurs due to the infiltration of malignant neoplastic leukocytes originated from the bone marrow into different skin layers such as dermis, epidermis, and subcutis ${ }^{7}$. In patients with LC, clinical symptoms are variable which include macules, papules, neoformation with the nodular aspect, ulcers and plaques ${ }^{8-10}$. According 


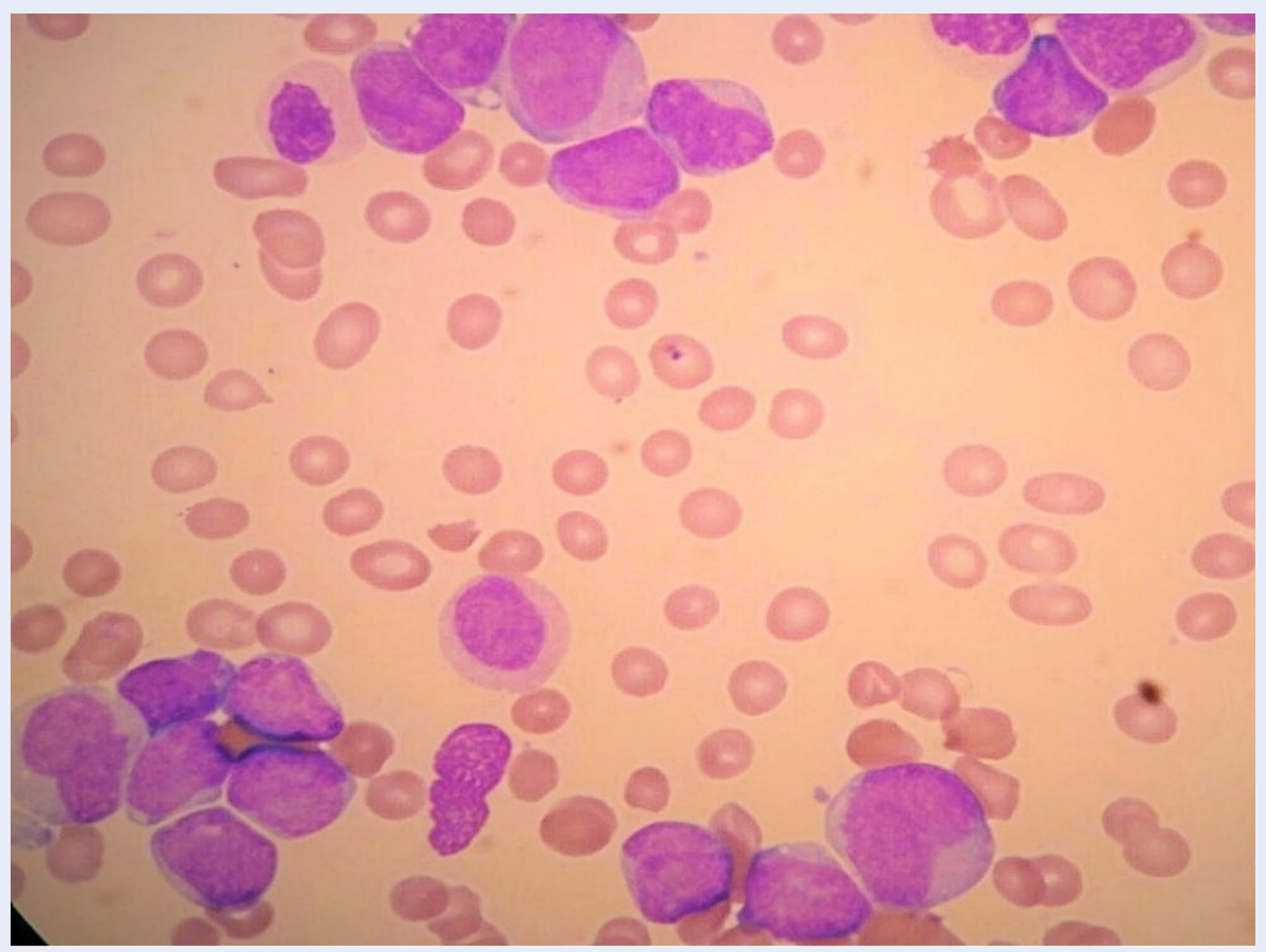

Figure 1: Blood film showing markedly elevated monoblasts and promonocytes.

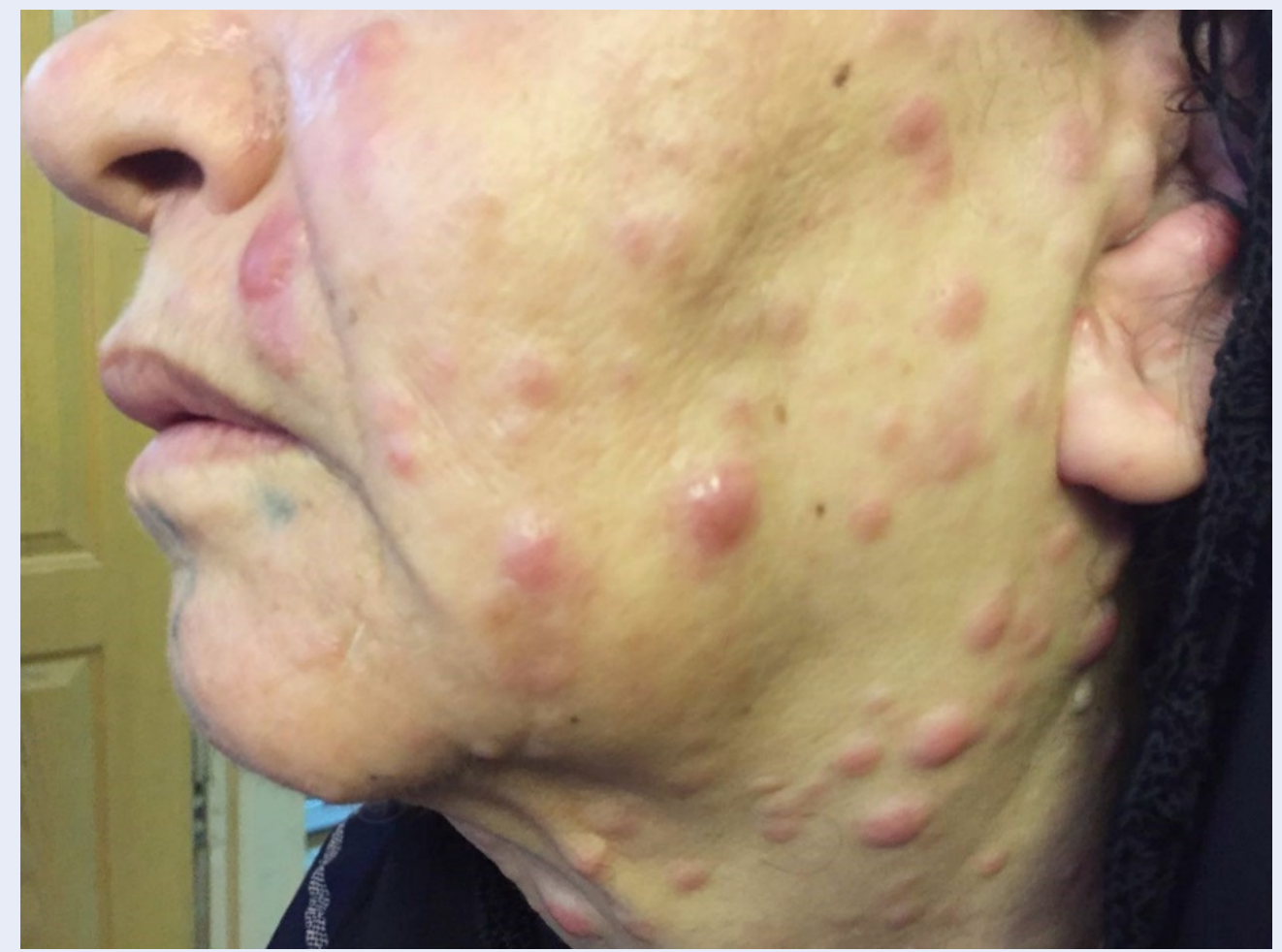

Figure 2: Multiple scattered erythematous and papulonodular rash on face and neck. 


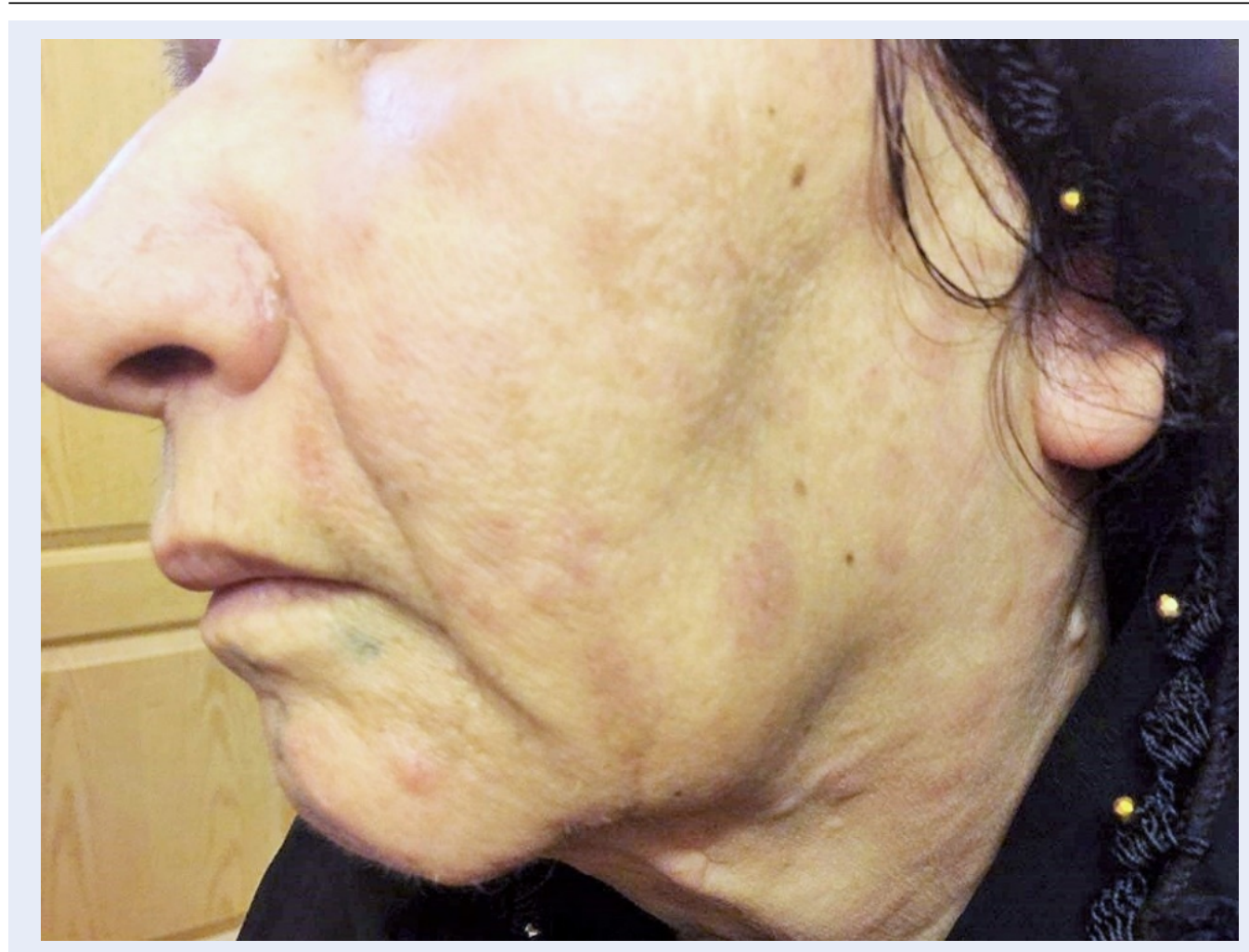

Figure 3: Clinical remission of skin lesions after the salvage therapy with FLAG regimens.

to the literature, the most common lesions are macula and neoformation with nodular character ${ }^{10}$. The differential diagnosis of LC to other cutaneous lymphomas (i.e., mycosis fungoides and Sézary syndrome) is based on symptoms such as erythematous or violaceous plaques, papules or nodules, which occur most frequently on face, chest or limbs, whereas, the typical clinical manifestations of mycosis fungoides and Sézary syndrome are respectively hypopigmented lesions and erythroderma ${ }^{11}$.

LC is more common in AML- than CML patients. Its prevalence in these patients is around 10 $15 \%{ }^{12}$. Chromosomal abnormalities (especially trisomy chromosome 8) are also associated with the progression of LC in patients with $\mathrm{AML}^{2}$. Due to the lack of a specific treatment and poor prognosis of LC, the typical leukemia treatments are generally used to improve skin lesions ${ }^{13}$. Based on the bone marrow status, the treatment can be varied in different patients. For examples, in patients not involved in bone marrow, an intensive AML chemotherapy is used when there is no bone marrow involvement, but LC shows resistance to the treatment, the approach is to use the total skin electron beam (TSEB) therapy to ensure the maximal control of the disease. If the bone marrow status indicates AML, then, hematopoietic stem cell transplantation (HSCT) is an excellent therapeutic approach ${ }^{14}$. However, using HSCT for older patients can result in severe inhibition of hematopoiesis. Therefore, in these patients, 5-azacytidine (5-Aza), a maintenance therapy, is a useful treatment option. 5-Aza, which is a hypomethylating agent, can regulate gene expression by suppressing DNA methylation $^{15}$. Cytarabine and fludarabine are two significant components of the chemotherapy regimens used in the treatment of leukemia and lymphoma. These chemotherapeutic agents prevent DNA synthesis by binding to cytosine bases and ribonucleotide reductase/ DNA polymerase ${ }^{16,17}$.

Katagiri and colleagues reported a woman with MS (myeloid sarcoma) and LC associated myelodysplastic syndrome. For the patient was prescribed 5-Aza following the induction therapy with daunorubicin and cytarabine. Consequently, LC vanished after these treatments ${ }^{15}$. Similarly, in 2017, Kara and colleagues used azacitidine therapy for a case of LC with AMLM4, but after the refractory to the therapy and the development of cutaneous, salvage therapy with cytarabine was proposed ${ }^{18}$. Therefore, in patients with relapsed and refractory AML, salvage chemotherapy regimens should be utilized. These regimes are 
as follows: EMA-86 (Mitoxantrone, Cytarabine, and Etoposide), FLAD (Fludarabine, Cytarabine and Liposomal daunorubicin), FLAM (Flavopiridol, Cytarabine and Mitoxantrone) and FLAG (fludarabine, cytarabine and granulocyte-colony stimulating factor $)^{19}$. Our case was unique for the following reasons: - Patient has acute myeloid leukemia (AML-M5)

- Cutaneous

- Complete remission of LC after salvage therapy

Our case accentuates the importance of clinical diagnosis and suggests considering LC patients as refractory leukemia for the use of salvage chemotherapy regimens.

\section{CONCLUSION}

Due to the absence of standard guidelines for the management of treatment, LC has a poor prognosis. In this study, the choice of appropriate treatments and the continuous follow-up have led to an improvement in leukemia cutis lesions.

\section{ABBREVIATIONS}

AML: acute myeloid leukemia

AMOL: acute monocytic leukemia

BMA: bone marrow aspiration

BMB: bone marrow biopsy

CAG: cytarabine, aclarubicin, and G-CSF

FAB: French-American-British

FLAG: fludarabine, cytarabine, and G-CSF

HSCT: Hematopoietic stem cell transplantation

LC: Leukemia cutis

MS: myeloid sarcoma

TSEB: total skin electron beam

\section{COMPETING INTERESTS}

The authors declare that they have no financial or other conflicts of interest.

\section{AUTHORS' CONTRIBUTIONS}

Mehrdad Payandeh \& Afshin Karami: Literature search, Clinical studies, Data acquisition, Data analysis; Afshin Karami: Manuscript preparation, Manuscript review, Guarantor; Noorodin Karami: Concepts, Design, Definition of intellectual content, Literature search, Manuscript editing; Soode Enayati, \& Mehrnoush Aeinfar: Manuscript editing, Literature search. All authors read and approved the final manuscript.

\section{ETHICS APPROVAL AND CONSENT TO PARTICIPATE}

Yes.

\section{REFERENCES}

1. Cho-Vega JH, Medeiros LJ, Prieto VG, Vega F. Leukemia cutis. Am J Clin Pathol. 2008;129(1):130-42. Available from: 10.1309/ WYACYWF6NGM3WBRT.

2. Rao AG, Danturty I. Leukemia cutis. Indian J Dermatol. 2012;57(6):504. Available from: 10.4103/0019-5154.103086.

3. Seok DK, Kee SY, Ko SY, Lee JH, Kim HY, Kim IS, et al. Leukemia cutis in a patient with acute monocytic leukemia diagnosed simultaneously with hepatocellular carcinoma: A case study. Oncol Lett. 2013;6(5):1319-22. Available from: 10.3892/ol. 2013.1580.

4. Vilaça S, Rosmaninho A, Amorim I, Selores M. leukemia cutis: first clue for an unsuspected diagnosis. J Am Acad Dermatol. 2012;66(4):AB55.

5. Creelan M, Nair M, Filicko-O'Hara MA. 68 Year-old Woman With Leukemia Under Her Skin. Med Forum. 2008;10(1):9. Available from: 10.29046/TMF.010.1.008.

6. Cibull TL, Thomas AB, O'Malley DP, Billings SD. Myeloid leukemia cutis: a histologic and immunohistochemical review. J Cutan Pathol. 2008;35(2):180-5.

7. Manzano MC, García LR, Pont JES, Mañana AIV, Sánchez JL. Rosacea-Like Leukemia Cutis: A Case Report. Am J Dermatopathol. 2016;38(8):e119-21. Available from: 10.1097/ DAD.0000000000000538.

8. Aguilera SB, Zarraga M, Rosen L. Leukemia cutis in a patient with acute myelogenous leukemia: a case report and review of the literature. Cutis. 2010;85(1):31-6.

9. Starnes AM, Kast DR, Lu K, Honda K. Leukemia cutis amidst a psoriatic flare: a case report. Am J Dermatopathol. 2012;34(3):292-4. Available from: 10.1097/DAD. $0 \mathrm{~b} 013 \mathrm{e} 31822 \mathrm{c} 3 \mathrm{c} 4 \mathrm{f}$.

10. Peña-Romero AG, Domínguez-Cherit J, Méndez-Flores $S$. [Leukemia cutis: clinical features of 27 mexican patients and a review of the literature]. Gac Med Mex. 2016;152(5):439-43.

11. Sambasivan A, Keely K, Mandel K, Johnston DL. Leukemia cutis: an unusual rash in a child. CMAJ. 2010;182(2):171-3. Available from: 10.1503/cmaj.090703.

12. Narayanan G, Sugeeth M, Soman LV. Mixed Phenotype Acute Leukemia Presenting as Leukemia Cutis. Case Reports in Medicine. 2016;2016:1298375. Available from: 10.1155/2016/ 1298375.

13. Whittaker S. Cutaneous lymphomas and lymphocytic infiltrates. Rook's Textbook of Dermatology. 2010;1:1-64. Available from: 10.1002/9781444317633.ch57.

14. Bakst RL, Tallman MS, Douer D, Yahalom J. How I treat extramedullary acute myeloid leukemia. Blood. 2011;118(14):3785-3793. Available from: 10.1182/blood2011-04-347229.

15. Katagiri T, Ushiki T, Masuko M, Tanaka T, Miyakoshi S, Fuse $\mathrm{K}$, et al. Successful 5-azacytidine treatment of myeloid sarcoma and leukemia cutis associated with myelodysplastic syndrome: A case report and literature review. Medicine (Baltimore). 2017;96(36):e7975. Available from: 10.1097/MD. 0000000000007975.

16. Lamba JK. Genetic factors influencing cytarabine therapy. Pharmacogenomics. 2009;10(10):1657-74. Available from: 10.2217/pgs.09.118.

17. Shao J, Zhou B, Chu B, Yen Y. Ribonucleotide reductase inhibitors and future drug design. Curr Cancer Drug Targets. 2006;6(5):409-31. Available from: 10.2174/ 156800906777723949.

18. Kara A, Belli AA, Karakuş V, Dere Y, Kurtoğlu E. A Case of Leukemia Cutis with Acute Myeloid Leukemia on Azacitidine Therapy. Turk J Haematol. 2017;34(2):192-3. Available from: 10.4274/tjh.2016.0220.

19. Ramos NR, Mo CC, Karp JE, Hourigan CS. Current approaches in the treatment of relapsed and refractory acute myeloid leukemia. J Clin Med. 2015;4(4):665-95. Available from: 10.3390/jcm4040665. 